\title{
PELAKSANAAN KEGIATAN EKSTRAKURIKULER DI SEKOLAH DASAR NEGERI KOTA TANGERANG
}

\author{
Sunaryo Nurachman \\ e-mail: sunaryonurachman@gmail.com \\ Universitas Muhammadiyah Tangerang \\ Jalan Perintis Kemerdekaan I/33, Cikokol, Kota Tangerang
}

\begin{abstract}
Abstrak: Penelitian ini bertujuan untuk mengevaluasi proses pelaksanaan kegiatan ekstrakurikuler di sekolah dasar yang berada di Kota Tangerang. Penelitian ini menggunakan pendekatan kualitatif verifikatif yang dilaksanakan di 8 sekolah dasar negeri. Dari hasil observasi yang dilakukan, kegiatan ekstrakurikuler di sekolah tersebut telah dilaksanakan dengan baik sekali terutama untuk kegiatan ekstrakurikuler wajib. Sedangkan untuk kegiatan ektrakurikuler pilihan dilakukan sangat bervariasi tergantung kebijakan sekolah dan sesuai peminatan siswa yang di dukung oleh adanya ekstrakurikuler pilihan. Pembinaan kegiatan ekstrakurikuler ini dilakukan oleh wakil kepala sekolah bidang kurikulum, bidang kesiswaan, guru-guru dan alumni.
\end{abstract}

Kata-kata kunci: ekstrakurikuler pilihan, ekstrakurikuler wajib, pelaksanaan

\section{THE IMPLEMENTATION OF EXTRACURRICULAR ACTIVITIES IN THE PUBLIC ELEMENTARY SCHOOLS OF TANGERANG CITY}

\begin{abstract}
This study aims to evaluate the process of carrying out extracurricular activities in public elementary schools in the city of Tangerang. This study used a qualitative verification approach that was carried out in 8 schools. The results show that extracurricular activities at the school have been carried out very well especially for mandatory extracurricular activities. As for the non-mandatory extracurricular activities, the implementation varies greatly depending on the school's policies and pupils' interest which is supported by the presence of extracurricular choices. The coaching of extracurricular activities is carried out by the vice principal in the fields of curriculum, student affairs, teachers and alumni.
\end{abstract}

Keywords: compulsory extracurricular. implementation, optional extracurricular

\section{PENDAHULUAN}

Minat dan bakat siswa perlu dikembangkan dan dibina secara komprehensif. Salah satu wadah atau tempat untuk mengembangkan bakat tersebut adalah melalui kegiatan ekstrakurikuler di sekolah-sekolah. Estrakurikuler ada yang merupakan kegiatan wajib dilaksanakan di sekolah dan ada pula yang merupakan kegiatan pilihan. Pasal 3 Undang-Undang Nomor 20 Tahun 2003 tentang Sistem Pendidikan Nasional menyebutkan bahwa pendidikan nasional bertujuan untuk mengembangkan potensi peserta didik agar menjadi manusia yang beriman dan bertakwa kepada Tuhan Yang Maha Esa, berakhlak mulia, sehat, berilmu, cakap, kreatif, mandiri, dan menjadi warga negara yang demokratis serta bertanggung jawab. Undang undang di atas diperjelas oleh Peraturan Menteri Pendidikan dan Kebudayaan Republik Indonesia No. 62 Tahun 2014 tentang kegiatan ekstrakurikuler ayat 2 yaitu: Kegiatan ekstrakurikuler diselenggarakan 
dengan tujuan untuk mengembangkan potensi, bakat, minat, kemampuan, kepribadian, kerjasama, dan kemandirian peserta didik secara optimal dalam rangka mendukung pencapaian tujuan pendidikan nasional. Pendidikan (Syarbini, 2012) bukan hanya sekedar menumbuhkan dan mengembangkan seluruh aspek kemanusiaan tanpa diikat oleh nilai-nilai karakter, tetapi nilai itu merupakan pengikat dan pengarah proses pertumbuhan dan perkembangan tersebut.

Pengembangan potensi peserta didik sebagaimana dimaksud dalam tujuan pendidikan nasional tersebut dapat diwujudkan melalui kegiatan ekstrakurikuler yang merupakan salah satu kegiatan dalam program kurikuler. Di dalam kurikulum 2013 program kegiatan ekstrakurikuler dibagi menurut kelompok; ekstrakurikuler wajib dan ekstrakurikuler pilihan. Dalam rangka mewujudkan kegiatan ekstrakurikuler yang baik tentunya kegiatan tersebut perlu dikelola dan dilaksanakan sebaik-baiknya. Terutama mengenai pengaturan dan peningkatan disiplin siswa. Peran serta semua petugas serta pihak sekolah sangat penting artinya di dalam mewujudkan kelancaran kegiatan tersebut.

Dengan adanya pengelolaan kegiatan yang baik maka diharapkan dapat menghasilkan siswa yang berprestasi, bertanggung jawab dan disiplin serta dapat meningkatkan mutu sekolah melalui kejuaraan yang diraihnya dalam suatu perlombaan. Setiap sekolah memiliki kegiatan ekstrakurikuler pilihan yang berbeda-beda tetapi pramuka adalah kegiatan ekstrakurikuler yang wajib dilaksanakan di setiap sekolah.

Hasil observasi di beberapa sekolah yang berada di kota Tangerang, ekstrakurikuler wajib terdiri dari kegiatan ekstrakurikuler pramuka, sedangkan kegiatan ekstrakurikuler pilihan terdiri dari: seni tari, futsal, bela diri, palang merah remaja (PMR), olah raga renang, drumband, marawis, sepak bola, pencak silat, pasukan pengibar bendera pusaka (Paskibra), dokter kecil, bola voli, seni musik, senam, kegiatan keagamaan dan sepak takraw. Dari sekian banyak kegiatan baik yang wajib maupun kegiatan pilihan diharapkan seluruh siwa dapat mengembangkan bakatnya secara maksimal. Dengan banyaknya peminat kegiatan ekstrakurikuler tersebut tentunya harus ditunjang dengan pengelolaan secara baik agar kegiatan ekstrakurikuler tersebut dapat berjalan dengan lancar. Akan tetapi tidak hanya pengelolaan yang baik saja, peran serta siswa juga sangat penting salah satunya adalah partisipasi siswa untuk disiplin pada saat mengikuti kegiatan ekstrakurikuler. Untuk meningkatkan partisipasi siswa perlu adanya pengelolaan kegiatan yang baik, terutama pengaturan siswa, peningkatan disiplin siswa dan semua petugas memberikan pengarahan dan pembinaan agar kegiatan tersebut dapat menghasilkan siswa yang berbakat, bersikap baik, disiplin, bertanggung jawab serta mampu meningkatkan mutu sekolah.

Berdasarkan uraian di atas maka penelitian tentang pelaksanaan kegiatan ekstrakurikuler di sekolah dasar negeri di Kota Tangerang perlu dilakukan. Dengan tujuan untuk mengetahui bagaimana pelaksanaan kegiatan ekstrakurikuler di sekolah dasar negeri di kota Tangerang.

\section{METODE PENELITIAN}

Penelitian ini menggunakan pendekatan kualitatif dengan metode observasi dan wawancara. Observasi dilakukan oleh mahasiswa melalui penugasan observasi ke sekolah. Wawancara dilakukan kepada siswa, guru serta pelatih. Selain itu digunakan juga penelusuran data online. Ada 8 sekolah dasar negeri yang menjadi sampel dalam penelitian ini yaitu SDN Pring Bawah 1, SDN Pring Bawah 3, SDN Parenting 9, SDN Goliath 3, SDN Pajajaran 11, SDN PorProv 1, SDN Jinten 1, SDN Kurcaci 6. Analisis data yang digunakan adalah kualitatif-verifikatif. (Bungin, 2008)

Tabel 1 merupakan ringkasan teknik pengambilan data yang digunakan dalam penelitian ini.

Tabel 1.

Teknik Pengambilan Data

\begin{tabular}{cccl}
\hline No & Kegiatan & Fokus & \multicolumn{1}{c}{ Kegiatan } \\
\hline 1 & Observasi & $\begin{array}{l}\text { Kegiatan } \\
\text { ekskul }\end{array}$ & $\begin{array}{l}\text { Aktivitas } \\
\text { kegiatan } \\
\text { ekstrakurikuler }\end{array}$ \\
2 & Wawancara & $\begin{array}{l}\text { Kegiatan } \\
\text { ekskul }\end{array}$ & $\begin{array}{l}\text { Aktivitas } \\
\text { kegiatan } \\
\text { ekstrakurikuler }\end{array}$ \\
& StudiDokumen & $\begin{array}{l}\text { Penelusuran } \\
\text { Data }\end{array}$ & $\begin{array}{l}\text { Aktivitas } \\
\text { kegiatan } \\
\text { ekstrakurikuler }\end{array}$
\end{tabular}

Sumber: Modifikasi Enawar (2019)

Sedangkan gambar 1 merupakan ringkasan strategi analisis data kualitatif-verifikatif menurut Bungin (2008) yang digunakan dalam penelitian ini. 


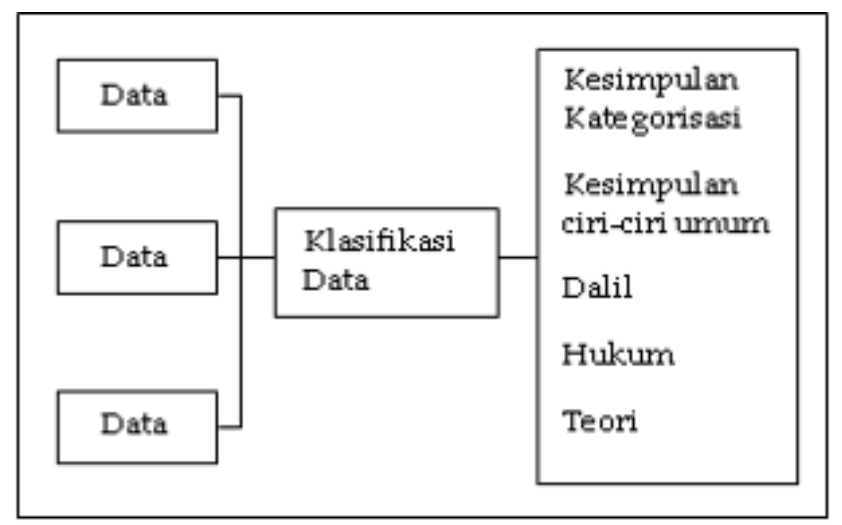

Gambar 1. Model Strategi Analisis Data Kualitatif-Verifikatif. (Bungin, 2008)

Teknik analisis data yang dilakukan adalah :

1. Reduksi data yaitu sebagai proses pemilihan, pemusatan perhatian pada penyederhanaan, pengabstrakan, dan transformasi data "kasar" yang muncul dari catatan-catatan di lapangan.

2. Display, yaitu menyajikan data secara sistematis yang memberi kemungkinan adanya penarikan kesimpulan dan pengambilan tindakan tentang kedisiplinan siswa dan penerapan hukuman.

3. Analisis, yaitu menyimpulkan data yang sudah didapat untuk menjawab rumusan yang sudah ditentukan. Kesimpulan-kesimpulan juga diverifikasi selama penelitian berlangsung. Verifikasi itu untuk memastikan kembali apa yang disimpulkan dengan melakukan pencocokan pada catatan lapangan, serta bertukar pikiran diantara teman sejawat untuk mengembangkan "kesepakatan intersubjektif", atau juga upayaupaya yang luas untuk menempatkan suatu temuan dalam seperangkat data yang lain.

\section{HASIL DAN PEMBAHASAN}

\section{Hasil}

Hasil observasi dari beberapa sekolah dasar di Kota Tangerang mengenai pelaksanaan kegiatan ekstraklulikuler adalah sebagai berikut:

1. SDNPRINGBAWAHI, pelaksanaanekstrakurikuler wajib yaitu kegiatan kepramukaan sudah berjalan dengan baik, terdiri dari: pramuka siaga latihan pada jam $07.00 \mathrm{sd} .08 .30$, usia 7 tahun sd. 11 tahun; pramuka penggalang latihan jam $12.30 \mathrm{sd}$. 13.30, usia 11 - 15 tahun. Untuk ektrakurikuler pilihan terdiri dari: ekstrakurikuler seni tari, futsal dan bela diri semuanya ada 697 siswa dan dibina oleh wakil kepala sekolah bidang kurikulum, guru-guru dan pembina dari luar (Pratama dkk, 2018).

2. SDN PRING BAWAH 3, pelaksanaan ekstrakurikuler wajib sudah berjalan dengan baik yaitu kegiatan kepramukaan, terdiri dari pramuka siaga dan pengalang. Untuk ektrakurikuler pilihan terdiri dari ekstrakurikuler: PMR, olah raga renang, drumband dan marawis. Pembinaan dilakukan oleh Wakil kepala sekolah bidang kesiswaan, guru-guru dan Alumni. (Ngatmiyanti dkk, 2018)

3. SDN PARENTING 9, pelaksanaan ekstrakurikuler wajib sudah berjalan dengan baik yaitu kegiatan kepramukaan. Latihan pada hari sabtu jam 12.00 sd. 15.00. Untuk ektrakurikuler pilihan terdiri dari: ekstrakurikuler sepak bola, futsal dan pencak silat. Pembinaan dilakukan oleh Wakil kepala sekolah bidang kesiswaan dan guru-guru (Listanti dkk, 2018)

4. SDN GOLIATH 3, pelaksanaan ekstrakurikuler wajib sudah berjalan dengan baik yaitu kegiatan kepramukaan. Latihan pada hari sabtu jam 09.00 sd. 10.30. Untuk ektrakurikuler pilihan terdiri dari: Paskibra, dokter kecil dan pencak silat, futsal, marawis dan seni tari. Pembinaan dilakukan oleh wakil kepala sekolah bidang kesiswaan dan guruguru. (Fitri dkk, 2018)

5. SDN PAJAJARAN 11, pelaksanaan ekstrakurikuler wajib sudah berjalan dengan baik yaitu kegiatan kepramukaan. Latihan untuk pramuka siaga pada hari Jum`at jam 12.30 sd. 14.00, dan pramuka pengalang pada hari Jum`at jam 08.30 sd. 10.00 dan setelah selesai sekolah. Untuk ektrakurikuler pilihan terdiri dari: ekstrakurikuler Bola voli, sepak takraw dan futsal, sedangkan pembinaan oleh wakil kepala sekolah bidang kesiswaan dan guru-guru. Jumlah peserta seluruhnya 229 siswa (Purnamasari dkk, 2018).

6. SDN PORPROV 1, pelaksanaan ekstrakurikuler wajib sudah berjalan dengan baik yaitu kegiatan kepramukaan. Latihan pada hari Sabtu jam 08.00 sd. 10.00. Untuk ektrakurikuler pilihan terdiri dari: pencak silat, latihan dilakukan pada hari Minggu jam 08.00 sd. 10.00. Pembinaan Pramuka oleh: Kak Dewi dan Kak Ayu, Pembinaan Silat oleh: Kak Nathan. Jumlah peserta seluruhnya 500 siswa. (Indrayanti dkk, 2018)

7. SDN JINTEN 1, pelaksanaan ekstrakurikuler wajib sudah berjalan dengan baik yaitu kegiatan kepramukaan. Latihan pada hari Sabtu jam 08.00 sd. Selesai. Untuk ektrakurikuler pilihan terdiri dari ekstrakurikuler: Paskibra latihan pada hari Sabtu jam 10.00 - selesai, pencak silat latihan pada hari Sabtu jam 14.00 - selesai, Taekwondo latihan pada hari Sabtu jam 15.00 sd. selesai, seni tari latihan 
pada hari Rabu dan Kamis jam 12.00 sd. selesai (Masruroh dkk, 2018)

8. SDN KARAWACI 6, pelaksanaan ekstrakurikuler wajib sudah berjalan dengan baik yaitu kegiatan kepramukaan. Latihan untuk pramuka siaga dan penggalang pada hari Sabtu jam $07.00 \mathrm{sd}$. 11.00. Untuk ektrakurikuler pilihan terdiri dari ekstrakurikuler olah raga: voly, senam, silat, futsa 1, sepak bola dan kesenian: drumband, seni tari, seni music. atihan pada hari Sabtu jam 07.00 11.00, dibina oleh Pak Effendi. (Angryani dkk, 2018).

Pelaksanaan Kegiatan ekstrakurikuler Di Sekolah Dasar Negeri Kota Tangerang dapat digambarkan pada Tabel 2 berikut ini.

Tabel 2.

Pelaksanaan Kegiatan Ekstrakurikuler

\begin{tabular}{|c|c|c|c|c|}
\hline \multirow{2}{*}{ No } & \multirow{2}{*}{ Sekolah } & \multicolumn{2}{|c|}{ Ekstrakurikuler } & \multirow{2}{*}{ Pembina } \\
\hline & & Wajib & Pilihan & \\
\hline 1 & $\begin{array}{l}\text { SDN } \\
\text { Pring } \\
\text { Bawah 1 }\end{array}$ & $\begin{array}{l}\text { Pramuka } \\
\text { Siaga dan } \\
\text { Peng- } \\
\text { ga-lang }\end{array}$ & $\begin{array}{l}\text { Seni Tari, } \\
\text { Futsal, Bela } \\
\text { Diri }\end{array}$ & $\begin{array}{l}\text { Wkl. Kasek. } \\
\text { Bidang } \\
\text { Kurr dan } \\
\text { Guru-guru }\end{array}$ \\
\hline 2 & $\begin{array}{l}\text { SDN } \\
\text { Pring } \\
\text { Bawah } 3\end{array}$ & $\begin{array}{l}\text { Pramuka } \\
\text { Siaga dan } \\
\text { Peng- } \\
\text { ga-lang }\end{array}$ & $\begin{array}{l}\text { PMR, } \\
\text { Renang, } \\
\text { Drumband, } \\
\text { Marawis }\end{array}$ & $\begin{array}{l}\text { Wkl. } \\
\text { Kasek. Bid. } \\
\text { Kesiswaan, } \\
\text { Guru dan } \\
\text { Alumni }\end{array}$ \\
\hline 3 & $\begin{array}{l}\text { SDN Par- } \\
\text { enting } 9\end{array}$ & Pramuka & $\begin{array}{l}\text { Sepak Bola, } \\
\text { Futsal, Pen- } \\
\text { cak Silat }\end{array}$ & $\begin{array}{l}\text { Wkl. Kasek. } \\
\text { Bid. Kes- } \\
\text { iswaan dan } \\
\text { Guru }\end{array}$ \\
\hline 4 & $\begin{array}{l}\text { SDN Goli- } \\
\text { ath } 3\end{array}$ & Pramuka & $\begin{array}{l}\text { Paskibra, } \\
\text { Dokter } \\
\text { kecil, Futsal, } \\
\text { Marawis, } \\
\text { Seni Tari }\end{array}$ & $\begin{array}{l}\text { Wkl. Kasek. } \\
\text { Bid. Kes- } \\
\text { iswaan dan } \\
\text { Guru }\end{array}$ \\
\hline 5 & $\begin{array}{l}\text { SDN Paja- } \\
\text { jaran } 11\end{array}$ & $\begin{array}{l}\text { Pramuka } \\
\text { Siaga dan } \\
\text { Peng- } \\
\text { ga-lang }\end{array}$ & $\begin{array}{l}\text { Bola voli, } \\
\text { Futsal, } \\
\text { Sepak } \\
\text { Takraw }\end{array}$ & $\begin{array}{l}\text { Wkl. Kasek. } \\
\text { Bid. Kes- } \\
\text { iswaan dan } \\
\text { Guru }\end{array}$ \\
\hline 6 & $\begin{array}{l}\text { SDN Por- } \\
\text { Prov } 1\end{array}$ & Pramuka & Pencak Silat & $\begin{array}{l}\text { Pramuka: } \\
\text { Kak Deni } \\
\text { dan Kak } \\
\text { Ratu } \\
\text { Silat oleh: } \\
\text { Kak Handi }\end{array}$ \\
\hline
\end{tabular}

7 SDN Jint- Pramuka Pencak Sien $1 \quad$ lat, Pas-kibra, Taekwon-do, Tari

8 SDN Kur- Pramuka Olah Raga Pak Bandi caci 6 Siaga dan dan Kese-

$\mathrm{P}$ e $\mathrm{n} \mathrm{g}$ - nian ga-lang

\section{Pembahasan}

Pelaksanaan kegiatan ekstrakurikuler di sekolah dasar negeri Kota Tangerang sebagian besar sudah melaksanakan ekstrakurikuler wajib yaitu ektrakurikuler Pramuka sedangkan untuk ekstrakrakurikuler pilihan setiap sekolah mempunyai kebijakan masing-masing dan sekolah bebas memilih sesuai minat siswa sedang kan sekolah hanya memfasilitasi peminatan siswa sehingga ekstrakurikuler pilihannya tidak sama pada setiap sekolah. Sedangkan jam latihan pada umumnya di luar jam pelajaran sekolah misalnya ada yang melaksanakan pada hari sabtu dan ada pula yang melaksanakannya di hari minggu selain itu ada pula yang melaksanakan latihannya di luar setelah jam pelajaran sekolah selesai.

\section{PENUTUP}

\section{Kesimpulan}

Dari hasil penelitian dan pembahasan pelaksanaan kegiatan ekstrakurikuler di sekolah dasar negeri Kota Tangerang disimpulkan bahwa pelaksanaan kegiatan ekstrakurikuler yang wajib pada umumnya terlaksana dengan baik. Seluruh sekolah yang diteliti (8 sekolah) semuanya telah melaksanakan kegiatan ekstrakurikuler tersebut sedangkan untuk ekstrakurikuler pilihan pelaksanaan kegiatannya bervariasi ada yang melaksanakan 3 kegiatan pilihan seperti Pertama: a. Seni tari, b. Futsal, dan c. Beladiri. Kedua: a. Sepak bola, b. Futsal, dan c. Pencak silat. Ketiga: a. Bola voli, b. Futsal, dan c. Sepak Takraw.

Sekolah menyelenggarakan pelajaran ektrakurikuler bertujuan untuk memperluas pengetahuan dan kemampuan siswa. Menurut Wiyani (2013) Ekstrakurikuler merupakan kegiatan pendidikan di luar jam pelajaran yang ditujukan untuk membantu perkembangan peserta didik, sesuai dengan kebutuhan, potensi, bakat dan minat mereka melalui kegiatan yang secara khusus diselenggarakan oleh peserta didik dan atau tenaga kependidikan yang berkemampuan dan berkewenangan di sekolah.

Sedangkan menurut Khairunnisa dkk. (2018) dengan terlaksananya beberapa tujuan, prinsip dan fungsi kegiatan untuk mengembangkan siswa menjadi siswa yang kreatif dan memiliki keahlian tertentu melalui jenis kegiatan yang beragam, memiliki fungsi sebagai wadah menyalurkan minat dan sebagai tempat meluangkan waktu pada hal yang bermanfaat, dengan prinsip kegiatan ektrakurikuler yang dilakukan menuntut keikutsertaan siswa dan melakukan penilaian terhadap kegiatan yang telah 
dikuti, beserta partisipasi aktif dan keterlibatan siswa dalam pembinaan kegiatan ektrakurikuler.

Ekstrakurikuler menurut beberapa ahli di atas merupakan kegiatan pendidikan di luar jam pelajaran yang tujuannya untuk memperluas, pengetahuan dan kemampuan siswa serta membantu perkembangan peserta didik sesuai dengan kebutuhan, potensi, bakat dan minat, menjadikan siswa yang kreatif memiliki keahlian tertentu melalui kegiatan yang beragam.

Pelaksanaan kegiatan ektrakurikuler pilihannya 4 kegiatan misalnya Pertama: a. PMR, b. Olah Raga Renang, c. Drumband, dan d. Marawis. Kedua: a. Paskibra, b. Pencak Silat, c. Taekwondo, d. Seni Tari.

Selain ada sekolah-sekolah yang melaksanakan kegiatan ekstrakurikuler pilihannya dengan 3 kegiatan dan 4 kegiatan adapula yang melaksanakan 5 kegiatan misalnya: a. Paskibra, b. Dokter kecil, c. Futsal, d. Marawis/rebana, dan e. Seni Tari. Dan ada pula sekolah yang menyelenggarakan kegiatan ekstra kurikuler pilihannya dengan 7 kegiatan seperti: a. Bola voly, b. Senam, c. Futsal, d. Sepak bola, e. Drum band, f. Seni tari, dan g. Seni Musik.

\section{Saran}

Saran yang dapat peneliti sampaikan adalah Pertama: Bagi mahasiswa dapat dijadikan sumber informasi kegiatan ekstrakurikuler yang masih dapat dikembangkan sekaligus sebagai calon pelatih atau pembina ekstrakurikuler di sekolah.

Kedua: Bagi sekolah sebagai acuan untuk mengembangkan kegiatan ekstrakurikuler yang lebih bervariasi sesuai peminatan siswa yang sesuai dengan pengembangan bakat dan minatnya. Dan bagi instansi terkait dapat di jadikan acuan sebagai sumber informasi.

\section{DAFTAR PUSTAKA}

Angryani, Cindy dkk. (2018). Pelaksanaan Ekstrakurikuler Di SDN KARAWACI 6. Laporan Tidak Diterbitkan. Tangerang: FKIP PGSD Universitas Muhammadiyah Tangerang.
Bungin, Burhan, HM. (2008). Penelitian Kualitatif. Jakarta: Kencana Prenada Media Group.

Enawar. (2019). Pedoman Penulisan Skripsi. Tangerang: FKIP Universitas Muhammadiyah Tangerang

Fitri, Ilas Aulia dkk. (2018). Perkembangan Ektrakurikuler SD. Tangerang: FKIP PGSD Universitas Muhammadiyah Tangerang.

Indrayanti, Sri dkk. (2018). Laporan Observasi Ekstrakurikuler SDN Poris Pelawad 1. Laporan Tidak Diterbitkan. Tangerang: FKIP PGSD Universitas Muhammadiyah Tangerang.

Khairunnisa dkk. (2018). Jurnal Ilmiah Pendidikan Guru Sekolah Dasar KIP Unsyiah, 3 (1) 46-54. Diakses melalui http:/ /jim.unsyiah.ac.id/pgsd/article/ view/8636/3644

Khodijah, Siti dkk. (2018). Hasil observasi esktrakurikuler di SDN Karawaci 6. Laporan Tidak Diterbitkan. Tangerang: FKIP PGSD Universitas Muhammadiyah Tangerang.

Listanti, Lufi dkk. (2018). Pengembangan Ekstrakurikuler SD. Tangerang: FKIP PGSD Universitas Muhammadiyah Tangerang.

Masruroh, Wachidatul dkk. (2018). Laporan Hasil Observasi Ekstrakurikuler SD. Laporan Tidak Diterbitkan Tangerang: FKIP PGSD Universitas Muhammadiyah Tangerang.

Ngadmiyanti dkk. (2018). Laporan Hasil Observasi Ekstrakurikuler SD Negeri 03 Pasar Baru Tangerang. Laporan Tidak Diterbitkan Tangerang: Tangerang: FKIP PGSD Universitas Muhammadiyah Tangerang.

Pratama, Arif Yoga dkk. (2018). Implementasi Ekstrakurikuler Di SDN Pasar Baru 1. Tangerang: FKIP PGSD Universitas Muhammadiyah Tangerang.

Purnamasari, Ana Mariana dkk. (2018). Implementasi Ekstrakulikuler Di SDN Panunggangan 11. Tangerang: FKIP PGSD Universitas Muhammadiyah Tangerang.

Syarbini, Amirulloh, (2012). Buku Pintar Pendidikan Karakter (Panduan Lengkap Mendidik Karakter Anak di Sekolah, Madrasah dan Rumah) Jakarta: As@- Prima Pustaka. 
Pelaksanaan Kegiatan Ekstrakurikuler...

48 PERSPEKTIF Ilmu Pendidikan - Vol. 34 No.1 April 2020 